\title{
PENGARUH NET PROFIT MARGIN (NPM), EARNING PER SHARE (EPS),RETURN ON INVESMENT (ROI),PERTUMBUHAN PENJUALAN, DEVIDENT PAYOUT RATIO (DPR) TERHADAP NILAI PERUSAHAAN \\ (STUDI KASUS PADA PERUSAHAAN MANUFAKTUR SEKTOR KIMIA,KEMASAN DAN PLASTIK YANG TERDAFTAR DI BURSA EFEK INDONESIA TAHUN 2010-2014)
}

\author{
SITI HAWA \\ Program Studi Akuntansi \\ Fakultas Ekonomi dan Bisnis \\ Universitas Islam Syekh Yusuf \\ Tangerang
}

\begin{abstract}
ABSTRAK
Penelitian ini bertujuan untuk menganalisis pengaruh variabel Net Profit Margin (NPM), dan Earning Per Share (EPS) Return on Invesment (ROI), Pertumbuhan Penjualan, dan Devident Payout Ratio (DPR) terhadap Nilai Perusahaan manufaktur yang terdaftar di Bursa Efek Indonesia (BEI) dalam pengamatan tahun 2010 - 2014.

Data yang digunakan merupakan data sekunder dan metode analisis yang digunakan yaitu analisis regresi linier berganda dengan bantuan program Econometric Views (Eviews) versi 8 untuk
\end{abstract}


memperoleh gambaran yang menyeluruh mengenai hubungan antara variabel satu dengan variabel yang lain. Sampel dalam penelitian ini terdiri dari duapuluh dua (22) perusahaan manufaktur kelompok Sektor kimia,plastik dan kemasan yang terdaftar di Bursa Efek Indonesia (BEI) dalam pengamatan 2010 sampai dengan 2014 dengan metode purposive sampling sebagai metode pengambilan sampel.

Hasil dari penelitian ini adalah: (1) Net Profit Margin (NPM) berpengaruh signifikan terhadap nilai perusahaan, (2) Earning Per Share (EPS) berpengaruh signifikan terhadap nilai perusahaan, (3) Return on Invesment (ROI) tidak berpengaruh signifikan terhadap nilai perusahaan, (4) Pertumbuhan Penjualan berpengaruh signifikan terhadap nilai perusahaan (5) Devident Per Share (DPR) tidak berpengaruh signifikan terhadap nilai perusahaan, Hasil analisis regresi secara simultan diperoleh hasil bahwa Net Profit Margin (NPM), Earning Per Share (EPS), dan Pertumbuhan Penjualan berpengaruh signifikan terhadap nilai perusahaan sedangkan Return on Invesment (ROI) dan Devident Per Share (DPR) secara tidak berpengaruh signifikan terhadap nilai perusahaan

Kata kunci : Net Profit Margin (NPM), Earning Per Share (EPS), Return on Invesment (ROI), Pertumbuhan Penjualan, Devident Per Share (DPR), Nilai Perusahaan 


\section{A. PENDAHULUAN}

Pada era globalisasi ini tingkat persaingan antar perusahaan semakin ketat. Perubahan selera konsumen, kemajuan teknologi, serta perubahan sosial ekonomi memunculkan tantangan-tantangan dan peluang dalam bisnis. Perusahaan harus dapat memanfaatkan kemampuan yang dimiliki agar dapat memenangkan persaingan dan memperoleh profit semaksimal mungkin yang merupakan salah satu tujuan didirikannya perusahaan. Hal ini akan membuat setiap perusahaan berusaha untuk meningkatkan kinerjanya semaksimal mungkin agar dapat memenangkan persaingan.

Nilai perusahaan merupakan persepsi investor terhadap perusahaan, yang sering dikaitkan dengan harga saham. Harga saham yang tinggi membuat nilai perusahaan juga tinggi. Tujuan utama perusahaan menurut theory of the firm adalah untuk memaksimumkan kekayaan atau nilai perusahaan (value of the firm) (Salvatore, 2005). Memaksimalkan nilai perusahaan sangat penting artinya bagi suatu perusahaan, karena dengan memaksimalkan nilai perusahaan berarti juga memaksimalkan kemakmuran pemegang saham yang merupakan tujuan utama perusahaan.

Rinnaya, Andini dan Oemar (2006) nilai perusahaan dapat dilihat dari harga sahamnya. Harga saham terbentuk atas permintaan dan penawaran investor, sehingga harga saham tersebut dapat dijadikan proksi nilai perusahaan. Nilai perusahaan mencerminkan asset yang dimiliki oleh perusahaan. Nilai perusahaan dapat dinilai dari 
harganya sahamnya yang stabil dan mengalami kenaikan dalam jangka panjang, harga saham yang tinggi membuat nilai perusahaan juga tinggi. Semakin tinggi nilai perusahaan mengindikasikan kemakmuran pemegang saham. Harga saham di pasar modal terbentuk berdasarkan kesepakatan antara permintaan dan penawaran investor, sehingga harga saham merupakan fair price yang dapat dijadikan nilai pererusahaan.

Ada beberapa konsep dasar penilaian yaitu : nilai ditentukan untuk suatu waktu atau periode tertentu, nilai harus ditentukan pada harga yang wajar, penilaian tidak dipengaruhi oleh kelompok pembeli tertentu. Secara umum banyak metode dan teknik yang telah dikembangkan dalam penilaian perusahaan, di antaranya adalah : a) pendekatan laba antara lain metode rasio tingkat laba atau price earning ratio, metode kapitalisasi proyeksi laba; b) pendekatan arus kas antara lain metode diskonto arus kas; c) pendekatan dividen antara lain metode pertumbuhan dividen; d) pendekatan aktiva antara lain metode penilaian aktiva; e) pendekatan harga saham; f) pendekatan economic value added (Suharli, 2002).

Ada beberapa rasio untuk mengukur nilai pasar perusahaan, salah satunya Tobin's $Q$. Rasio ini dinilai bisa memberikan informasi paling baik, karena dalam Tobin's $Q$ memasukkan semua unsur hutang dan modal saham perusahaan, tidak hanya saham biasa saja dan tidak hanya ekuitas perusahaan yang dimasukkan namun seluruh asset perusahaan. 


\section{B. KERANGKA TEORITIS}

\subsection{Nilai Perusahaan}

Tujuan utama perusahaan menurut theory of the firm adalah untuk memaksimalkan kekayaan atau nilai perusahaan (value of the firm) (Salvatore, 2010). Memaksimalkan nilai perusahaan sangat penting bagi perusahaan, karena dengan memaksimalkan nilai perusahaan berarti juga memaksimalkan kemakmuran pemegang saham yang merupakan hal penting yang harus dicapai oleh manajemen perusahaan (Brigham dan Daves, 2010). Memaksimalkan kemakmuran pemegang saham dapat diterjemahkan menjadi memaksimalkan harga saham perusahaan. Meskipun perusahaan memiliki tujuan-tujuan yang lain, namun memaksimalkan harga saham adalah tujuan yang paling penting (Brigham dan Houston, 2010).

Husnan (2008) menyatakan, yang dimaksud dengan nilai perusahaan merupakan harga yang bersedia dibayar oleh calon pembeli apabila perusahaan tersebut dijual.

Semakin tinggi nilai perusahaan maka semakin tinggi pula kemakmuran pemegang saham. Semakin tinggi harga saham maka nilai perusahaan juga akan semakin tinggi. Tetapi pada kenyataannya tidak semua perusahaan menginginkan harga saham yang tinggi karena kuatir tidak laku dijual. Hal ini terbukti dengan adanya 
perusahaan perusahaan go public sub sektor kimia, plastik dan kemasan yang terdaftar di BEI. Oleh karena itu harga saham harus optimal, tidak terlalu tinggi dan tidak terlalu rendah ( Ista Yansi Rinnaya,Rita Andini dan Abrar Oemar : 2016)

Dalam penelitian ini nilai perusahaan diukur dengan tobin $Q$, salah satu versi Tobin's $Q$ yang dimodifikasi dan disederhanakan oleh Chung \& Pruitt (1994) terhadap rumus yang dibuat oleh Lindenberg \& Ross (1981) adalah:

$$
\mathbf{Q}=(\mathbf{M V S}+\mathrm{D}) / \mathrm{TA}
$$

Sumber : Wolfe (2003)

\subsection{Profitabilitas}

Agus Sartono (2008), berpendapat bahwa alat yang digunakan menghitung profitabilitas :

1). Profit Margin

2). Net Profit Margin

3). Return On Equity

4).Return On Invesment

$$
\begin{aligned}
& =\frac{\text { EBIT }}{\text { Penjualan }} \\
& =\frac{\text { EAT }}{\text { Penjualan }} \\
& =\underline{\text { EAT }} \\
& =\frac{\text { EAT }}{\text { Total Aktiva }}
\end{aligned}
$$




\subsection{Net Profit Margin}

Menurut Alexander (2008: 200) Net Profit Margin (NPM) adalah rasio yang digunakan untuk menunjukkan kemampuan perusahaan dalam menghasilkan keuntungan bersih setelah dipotong pajak.

Menurut Sulistyanto (tanpa tahun: 7) angka NPM dapat dikatakan baik apabila $>5 \%$.

Rasio ini dapat dirumuskan sebagai berikut :

Net Profit Margin (NPM)= laba Bersih Setelah Pajak

Penjualan

sumber : Agus Sartono (2008)

\subsection{Earning Per Share (EPS)}

Menurut Garrison dan Noreen (2001:787) rumus untuk menghitung EPS suatu perusahaan adalah dengan membagi earning after tax (EAT) yang tersedia untuk pemegang saham biasa dengan jumlah saham biasa yang beredar selama satu tahun. Adapun rumus perhitungan laba per lembar saham atau earning per share (EPS) adalah sebagai berikut:

$$
\text { EPS }=\frac{\text { Laba Bersih / EAT }}{\text { Iumlah saham vang beredar }}
$$

Sumber : Menurut Garrison dan Noreen (2001:787) 


\subsection{Return On Invesment}

Menurut Kasmir (2013:201), hasil pengembalian investasi atau lebih dikenal dengan Returm On Invesment (ROI) merupakan rasio yang menunjukan hasil (return) atas jumlah aktiva yang digunakan dalam perusahaan. ROI juga merupakan suatu ukuran tentang aktivitas manajemen dalam mengelola investasinya, disamping itu hasil pengembalian investasi menunjukan produktivitas dari seluruh dana perusahaan, baik modal pinjaman maupun modal sendiri. Semakin rendah rasio ini, semakin kurang baik, demikian juga sebaliknya. Artinya rasio ini digunakan untuk mengukur efektivitas dari keseluruhan operasi perusahaan.

Return on Investment (ROI) merupakan bagian dari rasio profitabilitas. Profitabilitas adalah kemampuan perusahaan memperoleh keuntungan dalam hubungannya dengan penjualan, total aktiva maupun modal sendiri (Sartono, 2010).

Rumus yang digunakan untuk return on Invesment, sebagai berikut:

$$
\text { Return On Invesment }(\text { ROI })=\frac{\text { Laba bersih setelah Pajak }}{\text { Total Aktiva }}
$$

Sumber : Kasmir (2013:201) 


\subsection{Pertumbuhan Penjualan}

Berdasarkan Kamus Besar Ekonomi "Penjualan adalah suatu transaksi yangmelibatkan pengiriman atau penyerahan produk, hak, atau jasa dalam pertukaran kas, janji pembayaran, atau yang dapat disamakan dengan uang atau kombinasinya". Menurut Yadati dan Wahyudi (2006) "Transaksi penjualan barang dagang dalam perusahaan dagang dapat dilakukan baik secara tunai maupun secara kredit, atau sebagaian secara tunai dan sisanya dibayar secara kredit". berikut:

Tingkat pertumbuhan penjualan dihitung dengan rumus sebagai

\begin{tabular}{|c|}
\hline $\mathrm{g}=\frac{\mathrm{S} 1-\mathrm{S} 0 \times 100 \%}{\mathrm{~S} 0}$ \\
Sumber : Horne (2005)
\end{tabular}

\subsection{Devident Payout Rasio (DPR)}

Dividen adalah laba yang diperoleh perusahaan untuk dibagikan kepada pemegang saham.

Menurut Lukas Setia Atmaja (2003: 285) rasio antara dividen dan laba bersih sering disebut sebagai Dividend Payout Rasio (DPR), yang persamaannya adalah :

$$
\text { DPR }=\frac{\text { Total Devident }}{\text { Net Income }}
$$

Sumber : Lukas Setia Atmaja (2003: 285) 


\section{Kerangka Pemikiran}

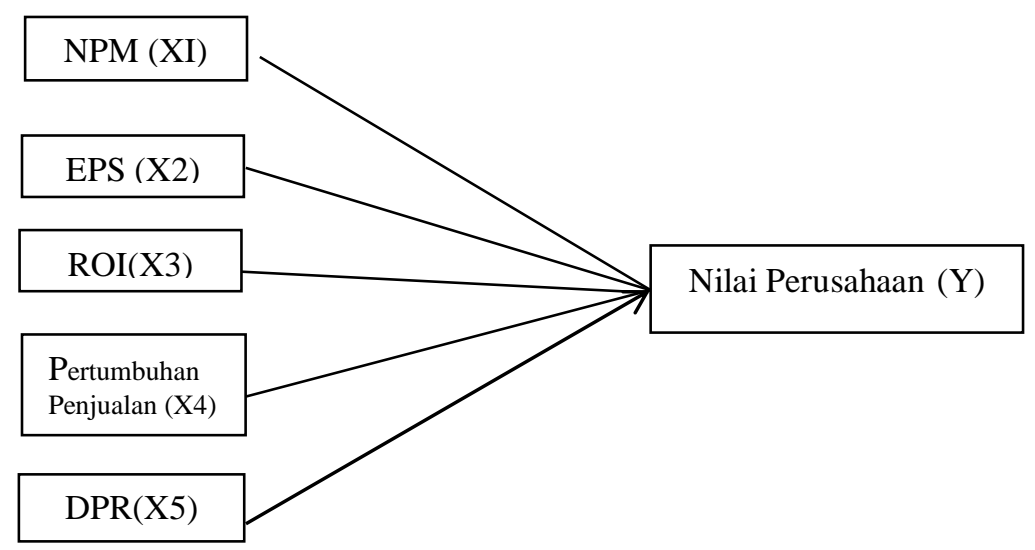

\section{METODE PENELITIAN}

Metode penelitian terdiri dari beberapa unsur antara lain meliputi :

1. Tipe Penelitian

Penelitian ini menggunakan tipe penelitian deskriptif dengan pendekatan kuantitatif. Metode Penelitian Kuantitatif, sebagaimana dikemukakan oleh Sugiyono (2012: 8) yaitu : "Metode penelitian yang berlandaskan pada filsafat positivisme, digunakan untuk meneliti pada populasi atau sampel tertentu,pengumpulan 
data menggunakan instrumen penelitian, analisis data bersifat kuantitatif/statistik, dengan tujuan untuk menguji hipotesis yang telah ditetapkan".

Berdasarkan teori tersebut, penelitian deskriptif kuantitatif, merupakan data yang diperoleh dari sampel populasi penelitian dianalisis sesuai dengan metode statistik yang digunakan.

2. Teknik Pengumpulan Data

Dalam penelitian ini peneliti menggunakan metode statistik yaitu dengan memperoleh data yang berbentuk angka atau data kualitatif yang diangkakan serta melakukan pengujian terhadap hipotesis, dengan menggunakan sampel yang mencerminkan pada populasi dengan menggunakan data sekunder. Teknik pengumpulan data yang dilakukan pada penelitian ini yaitu mengumpulkan data sekunder dari situs Bursa Efek Indonesia (BEI) dan website www.idx.co.id berdasarkan kriteria yang dikehendaki oleh peneliti. Data sekunder pada penelitian ini berupa laporan tahunan (annual report) pada perusahaan manufaktur periode 2010-2014 yang telah dipulikasikan. Peneliti mengumpulkan informasi data kuantitatif perusahaan. Jenis data yang digunakan dalam penelitian ini adalah data panel dimana disusun berdasarkan laporan keuangan 22 
perusahaan manufaktur sub sektor kimia, plastik dan kemasan yang terdaftar di BEI (Bursa Efek Indonesia) periode 2010-2014 untuk mengetahui pengaruh variabel Net rofit Margin (NPM), Earning Per Share (EPS), Return on Invesment (ROI), Pertumbuhan Penjualan dan Devident Payout Ratio (DPR).

\section{E.HASIL PENELITIAN}

Profitabilitas Net Profit Margin (NPM) mempunyai pengaruh positif signifikan terhadap nilai perusahaan karena nilai signifikan lebih kecil dari 0,05. Sehingga hipotesis yang menyatakan Net Profit Margin (NPM) berpengaruh signifikan terhadap nilai perusahaan pada perusahaan manufaktur periode 2010-2014 diterima. Dengan demikian jika Net Profit Margin (NPM) dapat dikatakan bernilai kecil untuk perusahaan manufaktur sub sektor industri, plastik dan kemasan untuk periode 2010-2014. Hasil penelitian ini sejalan dengan hasil peneltiian yang dilakukan oleh Munawaroh dan Priyadi (2014) yang menyatakan Net Profit Margin (NPM) berpengaruh terhadap nilai perusahaan.

Variabel Earning Per Share (EPS) berpengaruh signifikan terhadap nilai perusahaan karena nilai signifikan lebih kecil dari 0,05. Sehingga hipotesis yang menyatakan EPS berpengaruh signifikan terhadap nilai perusahaan pada Perusahaan Manufaktur periode 2010-2014 diterima. Dengan demikian pihak investor sangat memperhitungkan laba yang diperoleh perusahaan dalam 
mengambil keputusan investasinya. Jika laba suatu perusahaan naik maka mengindikasikan kinerja perusahaan baik. Hasil penelitian ini sejalan dengan hasil penelitian yang dilakukan Sari dan Sidiq yang menyatakan Earning Per Share (EPS) berpengaruh signifikan terhadap nilai perusahaan.

Variabel Return On Invesment (ROI) berpengaruh tidak signifikan signifikan terhadap nilai perusahaan karena nilai signifikan lebih besar dari 0,05 . Sehingga hipotesis yang menyatakan ROI berpengaruh terhadap nilai perusahaan pada Perusahaan Manufaktur periode 2010-2014 tidak dapat diterima. Hasil penelitian ini berbeda dengan hasil penelitian yang dilakukan Irvaniawati Dan Utiyati (2014) yang menyatakan Return On Invesment (ROI) berpengaruh terhadap nilai perusahaan.

Variabel Pertumbuhan Penjualan berpengaruh signifikan terhadap nilai perusahaan karena nilai signifikan lebih kecil dari 0,05. Sehingga hipotesis yang menyatakan Pertumbuhan Penjualan berpengaruh signifikan terhadap nilai perusahaan pada Perusahaan Manufaktur periode 2010-2014 diterima. Hasil penelitian ini berbeda dengan hasil penelitian yang dilakukan Darmawan (2015) yang menyatakan pertumbuhan penjualan tidak berpengaruh pada nilai perusahaan.

Variabel Devident Per Share (DPR) tidak berpengaruh signifikan terhadap nilai perusahaan karena nilai signifikan lebih besar dari 0,05. Sehingga hipotesis yang menyatakan Devident Per 
Share berpengaruh tidak signifikan terhadap nilai perusahaan pada Perusahaan Manufaktur periode 2010-2014 diterima. Hasil penelitian ini berbeda dengan hasil penelitian yang dilakukan Irvaniawati dan Utiyati yang menyatakan Devident Payout Ratio (DPR) berpengaruh terhadap nilai perusahaan.

Hipotesa penelitian menunjukan bahwa bahwa variabel NPM,EPS,ROI, Pertumbuhan Penjualan dan DPR berperaruh tidak signifikan terhadap nilai perusahaan manufaktur sub sektor kimia, kemasan dan platik yang terdaftar di Bursa Efek Indonesia peride tahun 2010 - 2014.

\section{F. KESIMPULAN}

Variabel Net Profit Margin (NPM) mempunyai pengaruh signifikan terhadap nilai perusahaan. Sehingga hipotesis yang menyatakan NPM mempunyai pengaruh signifikan terhadap nilai perusahaan pada Perusahaan Manufaktur periode 2010-2014 diterima.

Variabel EPS berpengaruh signifikan terhadap Nilai Perusahaan Sehingga hipotesis yang menyatakan EPS berpengaruh signifikan terhadap Nilai Perusahaan pada Perusahaan Manufaktur periode 2010-2014 diterima.

Variabel ROI berpengaruh tidak signifikan terhadap Nilai Perusahaan Sehingga hipotesis yang menyatakan ROI berpengaruh signifikan terhadap Nilai Perusahaan pada Perusahaan Manufaktur 
periode 2010-2014 ditolak

Variabel Pertumbuhan Penjualan berpengaruh signifikan terhadap Nilai Perusahaan. Sehingga hipotesis yang menyatakan Pertumbuhan Penjualan berpengaruh signifikan terhadap Nilai Perusahaan pada Perusahaan Manufaktur periode 2010-2014 diterima Variabel DPR berpengaruh tidak signifikan terhadap Nilai Perusahaan. Sehingga hipotesis yang menyatakan DPR berpengaruh signifakn terhadap Nilai Perusahaan pada Perusahaan Manufaktur periode 2010-2014 ditolak

\section{DAFTAR PUSTAKA}

Alexander, Gordon J, William F. Sharpe and Jeffery V Bailey.2000. Fundamentals of Investment. $3^{\text {rd }}$ ed. New Jersey: Prentice-Hall, Inc

Ghozali, Imam, 2001, Aplikasi Analisis Multivariate dengan program SPSS, Badan Penerbit UNDIP, Semarang.

Husnan, Suad. 2008, Manajemen Keuangan: Teori dan Penerapan Buku 1, Edisi 4, BPFE Yogyakarta

Ista Yansi Rinnaya, Rita Andini dan Abrar Oemar, (2006), Pengaruh Profitabilitas, Rasio Aktivitas, Keputusan Pendanaan, Keputusan Investasi Terhadap Nilai Perusahaan (Studi Empiris Pada Perusahaan Manufaktur Yang Terdaftar Di BEI Tahun 2010-2014),Journal Of 
Accounting, Volume 2 No.2

D. Irayanti., A.L. Tumbel (2014), Analisis Kinerja Keuangan Pengaruhnya terhadap Nilai Perusahaan pada Industri Makanan dan Minuman di BEI, Jurnal EMBA Vol.2 No.3 ISSN 2303-1174

Irvaniawati danSri Utiyati (2014), Analisis Pengaruh Kebijakan Hutang, Kebijakan Investasi, dan Kebijakan Dividen Terhadap Nilai Perusahaan, Jurnal Ilmu \& Riset Manajemen Vol. 3 No. 6

Sugiyono. 2010. Metode Penelitian Kuantitatif Kualitatif dan R\&D. Alfabeta. Bandung

Sartono, 2010 Sartono, Agus. Manajemen Keuangan Teori dan Aplikasi. Yogyakarta: BPEF-YOGYAKARTA, 2010. 